\title{
LA DISTRIBUCIÓN DEL INGRESO EN MÉXICO
}

\author{
Adalberto García Rocha* \\ El Colegio de México
}

\section{INTRODUCCIÓN}

El objetivo principal de esta nota es describir un experimento de aplicación a la distribución personal del ingreso en México de un modelo estadístico ya bien conocido en la literatura. Aunque la idea es tan original como la rueda, en el medio local el estudio del proceso que genera la distribución es todavía terreno fértil. Para estudiar las causas de la distribución, el paso preliminar es precisamente la exploración estadística del proceso, que permita luego hurgar en el mecanismo causal subyacente. En esta nota, después de una breve dosis de lírica, se examina la posición comparativa internacional de México en cuanto a la distribución del ingreso, la evolución de ésta en los últimos decenios, el ajuste de la distribución lognormal a las observaciones, y por último una discusión breve sobre las políticas locales de empleo en conexión con la distribución del ingreso.

La distribución del ingreso es un tema que de un modo $\mathbf{u}$ otro preocupa a todos. Toca inclusive los espacios vitales de los economistas y los tomadores de decisiones. Tal vez por los conflictos que produce, en el mundo moderno duró poco la política económica basada en la premisa de que cada individuo debía recibir el equivalente de su contribución al producto económico, de acuerdo con las libres fuerzas del mercado. La impaciencia y el escepticismo en el libre cambio orillaron a la mayoría de los gobiernos a planear para crecer más aprisa y corregir los vicios distributivos. Esto sucedió inclusive en los Estados Unidos. Los mercados no funcionaban al gusto de la masa y por lo tanto "había que moderar el laissez faire." 1

En México sucedió algo semejante, con el matiz inevitable del inge-

* Agradezco a Andrea Morton, Gustavo Cabrera, Manuel Gollás y Pedro Uribe sus interesantes comentarios a la primera versión de este trabajo.

1 Véase una reseña interesante en Jan Tinbergen, "From Economic to Socioecomic Development", en Annals of The New York Academy of Sciences, Vol. 184, Nueva York, junio 7 de 1971, pp. 409-417; también R. H. Tawney, "The Religion of Inequality", en Wealth, Income and Inequality, A. B. Atkinson (Comp.), Middlesex, Penguin Books, 1973. En M. Bronfrenbrenner, Income Distribution Theory, Aldine-Atherton, 1971, Caps. 1, 2 y 3, puede leerse un buen recuento de las discusiones sobre el tema distributivo en Estados Unidos y Europa desde principios de siglo. 
nio local. Los gobiernos inmediatos siguientes a la revolución de 1910, tal vez por la intransigencia de la población de esos años, pretendieron resolver los conflictos sobre la propiedad y la riqueza repartiendo lo que podían. Después, con la llegada de las máquinás al país, la política económica se "sofisticó". Se decidió que no debía acudirse a expedientes tan elementales como al principio; las decisiones debían pensarse bien, ser científicas. Convencidas del imperativo de planear, las fuerzas vivas, años después dispusieron como primera providencia la confección de las cuentas nacionales. Con nociones keynesianas adaptadas debidamente a las peculiaridades de la economía mexicana se armó una política de desarrollo "estabilizador". Había que lograr una buena tasa de crecimiento con estabilidad de precios y de la paridad cambiaria; para ello, el aparato bancario debía tener como función el financiamiento del desarrollo económico. Estas ideas maduraron a lo largo de varias etapas e inclusive dieron lugar a un ingenioso lenguaje metafórico. Una vez cubierta la etapa de despegue, decían, ante cualquier signo de sobrecalentamiento, había que aplicar los frenos inflacionarios para impedir recesos y atonías desagradables. Así lo requerían las reglas del juego de una economía mixta.

Al mismo tiempo, la planeación se automatizó y la información se convirtió en el ámbar gris de las dependencias públicas y privadas. Sin embargo, a medida que la cibernética se fue incorporando a la toma de decisiones, se vio desaparecer la prisa por atender los problemas distributivos. En realidad, las circunstancias en toda América Latina fueron semejantes. Por todos lados surgieron del underground criticas que censuraban a los planificadores por haber soslayado los problemas de las mayorías. Algunos, con gran audacia, juzgaron de doloso el descuido y censuraron que los teóricos oficiales se hayan dedicado durante tanto tiempo a desentrañar la relación entre la tasa de interés y la fuga de capitales, mientras las ciudades se hacinaban y en las calles proliferaban los vendedores de frutas. Para dar sustancia a los argumentos se ideó inclusive una nueva teoría marginalista, pero esta vez referida a los marginados. También, una corriente de pensamiento latinoamericano creó toda una discusión alrededor de la distribución del ingreso, pero al nivel de muy grandes agregados: el comercio y la dependencia entre países débiles y fuertes. Las grandes potencias - sostenía esta escuela- debían convencerse de que la miseria no era parte del folklor. Ante semejantes presiones, los políticos de todos los ámbitos asimilaron la crítica en su retórica; dieron su palabra de caballeros de que el desarrollo "no se apoyaría sobre los hombros de los pobres", y dispusieron que los teóricos oficiales dedicaran la atención debida al asunto.

En algunos casos las críticas dieron lugar a apologías, aunque a veces también a reacciones menos receptivas. Según los planificadores, podía ser que la distribución del ingreso se concentrara cada vez más, pero el ingreso de todos crecía y por lo tanto los pobres de ahora lo eran menos que antes. La concentración del ingreso era un costo ine- 
vitable y natural del crecimiento. Sus causas no debían achacarse frívolamente a la política económica. La economía debía crecer para que el ingreso se desparramara a los pobres, pero sin sacrificar el ahorro, piedra angular del desarrollo. Otras apologías poco menos cuidadosas sostenían que en este momento histórico sólo se podía distribuir la miseria. ${ }^{2}$

Por fortuna, al menos en México se admite ahora que la pobreza y el desempleo pueden ser problemas graves. Su costo económico ya ha sido reconocido. Sin duda, el auge reciente de ciencias y científicos en la busca de soluciones es reflejo de esta nueva toma de conciencia.

\section{LA Distribución en MÉxico y otros países}

En atención a la respetable filosofía que aconseja ir de lo general a lo particular, conviene empezar por ver la posición de México en relación con otros países americanos y europeos en cuanto a la distribución personal del ingreso. Para ello se presenta el cuadro 1, que contiene el ingreso per capita y el coeficiente de concentración de Gini para cada uno de varios países. Por ahora baste recordar que el índice de Gini vale 0 cuando la concentración es nula (todos ganan ingresos iguales) o tiende a 1 cuando la concentración tiende al máximo, que es cuando un grupo de población acapara todo.

Se ha dicho repetidamente que el simple ingreso per capita no dice gran cosa del nivel de desarrollo de un país, sino que es necesario asociarlo a la distribución. Sin embargo, cuando el ingreso per capita es muy bajo, la situación de un país puede ser crítica, aun cuando la concentración sea nula. De cualquier modo, el lector puede lograr comparaciones mejores si pone un ojo en el coeficiente de concentración y el otro en el ingreso per capita que aparecen en el cuadro 1.

El índice de concentración muestra que México comparte honores dudosos con Brasil, Colombia, Bolivia, Ecuador y Perú, con este último a la cabeza. Sin embargo, con el ojo derecho vemos que en el caso de México el ingreso es mayor. En este país hay más que repartir que en los países latinoamericanos restantes, salvo Argentina y Venezuela. Para tener idea de las proporciones, obsérvese que Bolivia y Estados Unidos están más o menos en los extremos opuestos. ${ }^{3}$

2 En C. G. Langoni, Income Distribution and Economic Development in Brasil, Oficina de Información del Banco Nacional de Habitaçâo (1973), Río de Janeiro, pueden verse los argumentos más decantados. En un pasaje, Langoni, en defensa de la política salarial brasileña, aconseja que ". .cualquier análisis honesto de la relación entre las políticas económicas y los cambios en la distribución del ingreso debe tomar en consideración la contribución de todos los períodos, buscando ponderar los efectos negativos y positivos de cada factor en todas las etapas". En otras palabras, el análisis debe hacerse con mucho cuidado.

3 El lector interesado puede ver, además de la fuente citada en el cuadro, S. Jain y A. E. Tiemann, Size Distribution of Income: Compilation of Data, BIRF, Development Research Center, 1973. 
Cuadro 1

MÉxico: Ingreso per capita E ÍNDICE de CONCENTRACIÓN, 1968

\begin{tabular}{|c|c|c|}
\hline Pais & Indioe de voncentrasion & $\operatorname{Ingreso}_{(d \sigma 1 \mathrm{per} \text { ops) }}$ \\
\hline Colonbia & 0.52 & 299 \\
\hline Bolivia & 0.53 & 151 \\
\hline Eorrador & 0.52 & 196 \\
\hline Pari & 0.63 & 246 \\
\hline Costa Rica & 0.50 & 384 \\
\hline Brasil & 0.55 & $271^{-9}$ \\
\hline chile & 0.45 & 449 \\
\hline México & 0.53 & 511 \\
\hline Venezcela & 0.44 & 803 \\
\hline Argontine & 0.43 & 609 \\
\hline Estadios Unidod & 0.35 & 3578 \\
\hline Franoia & 0.33 & 1927 \\
\hline Alementa Foderal & 0.47 & 1682 \\
\hline
\end{tabular}

Fuente: Polibio Córdova, Análisis econométrico de la distribución de ingresos, Departamento Administrativo Nacional de Estadística (DANE), Bogotá, 1973, pp. $112-114$

a Datos de 1967.

Según el cuadro, la concentración parece estar en relación inversa con el monto del ingreso per capita. Al parecer, donde hay más que repartir el reparto es mejor. Esto no debe confundirse con el argumento de los teóricos oficiales, que se refiere a la relación entre la velocidad de crecimiento del ingreso, no a su monto, y la concentración. Para conciliar los datos con lo que dicen los apologistas, debe entonces suponerse que en el futuro de los países donde la concentración aumenta hay una etapa redistributiva. El ingreso seguirá concentrándose hasta llegar a cierto nivel y luego empezará a redistribuirse cada vez más equitativamente. Como el advenimiento de tal etapa depende de la política económica, basada desde luego en inalienables argumentos científicos, a los hacedores de decisiones les falta aclarar cómo se establece la longitud del período de concentración creciente. Asimismo, convendría saber la magnitud máxima de la concentración que se habrá de alcanzar antes de la llegada del período de gracia, para que una vez iniciado pueda hacerse un cálculo numérico de la desaparición progresiva del número de pobres. Inclusive, si los recursos econométricos lo permitieran, convendría saber quiénes van a contribuir más al índice de Gini, para infundir paciencia en los afectados.

Como se verá luego, la distribución del ingreso en México es muy singular. No muestra estabilidad o lentitud de cambio como se observa en otros países. De las estadísticas recogidas se infiere que durante los años 60 el reparto del ingreso familiar mejoró. Este cambio habla elogiosamente de la política económica en uno de los renglones más vigilados por los inconformes, $\mathrm{y}$ es ciertamente inusitado porque hasta 
principios del decenio mencionado la concentración había aumentado dramáticamente. Algo debió suceder en el proceso económico que invirtió la tendencia de la distribución. Si se lograra descubrir qué fue, se tendría buena base para formular una política y para obligar a los neomarginalistas a revisar sus críticas. Antes de continuar debe advertirse al lector que en este trabajo no se llega a descubrimiento tan interesante.

\section{LOS CAMBIOS EN LA DISTRIBUCIÓN}

Cualquier distribución de tamaños, como la del ingreso, la población por edades, las ciudades por número de habitantes, las industrias por monto de su producto, etc., debe verse como el resultado de un proceso o cadena causal en el tiempo. Las distribuciones observadas son puntos en la historia de tal proceso y la clave del asunto consiste en explicarlo, una vez analizadas sus propiedades estadísticas.

La teoría económica no ha avanzado mucho en el sentido de explicar las distribuciones de tamaños de algunas variables económicas fundamentales. Por ejemplo, la distribución de tamaños de empresas implícita en el modelo neoclásico no está determinada unívocamente. ${ }^{4}$ En el caso de la distribución del ingreso el avance teórico es menor. Aunque los padres fundadores de la economía iniciaban sus consideraciones alrededor del tema distributivo, al final no ha quedado muy claro cómo se genera la distribución. La teoría de Ricardo, y las aportaciones posteriores a ella, referente a la distribución funcional del ingreso es un buen intento, pero la idea de que en circunstancias de competencia perfecta hay una ley natural (de productividades marginales) que genera la distribución es poco convincente. Cuesta trabajo creer que la distribución no es un fenómeno altamente político y de conflictos de intereses.

Estas circunstancias son probablemente la causa de que en la teoría moderna del bienestar se hayan hecho varios intentos por introducir explícitamente la distribución personal del ingreso, ante las limitaciones del criterio de bienestar óptimo paretiano. Así, se han concebido índices de desigualdad normativos, interconstruidos en una función de bienestar social relacionada inversamente con la concentración del ingreso. La idea se basa en el principio de que la desigualdad constituye un desperdicio, es decir, con menos ingreso (un seudoingreso) y una mejor distribución, se puede alcanzar un bienestar social mayor. ${ }^{5}$

4. En H. Lydall, "A Theory of Distribution and Growth with Economies of Scale", The Economic Iournal, marzo de 1971, se encuentra una discusión interesante de cómo introducir en forma explícita la distribución de tamaños de las empresas en el modelo neoclásico. Véase también Irma Adelman, "A Stochastic Analysis of the Size Distribution of Firms", en C. G. Archibald (Comp.), The Theory of the Firm, Middlesex, Penguin Books, 1971.

5 Véase A. B. Atkinson, "On the Measurement of Inequality", en Wealth Income and Inequality, A. B. Atkinson (Comp.), Middlesex, Penguin Book, 
Sin embargo, subsiste el hecho de que la teoría económica actual es un armazón de modelos esencialmente determinísticos. No se ha avanzado mucho en la construcción de modelos estadísticos del proceso económico que hagan manejable la teoría del equilibrio general. Las distribuciones del ingreso y las industrias por tamaños son dos casos donde la teoría se ha orientado más por la investigación de carácter estadístico. En este enfoque, las leyes más conocidas sobre la distribución del ingreso son la de Pareto y los procesos aleatorios multiplicativos que generan una distribución lognormal (distribución normal del logaritmo de una variable aleatoria). Pareto, como es bien sabido, afirmaba que la proporción de individuos con ingreso mayor a cierto nivel decrece geométricamente con el ingreso. A mayor nivel de ingresos hay una proporción cada vez menor de personas que lo reciben y el índice de Pareto es precisamente la tasa de disminución de la proporción de personas. Su valor se supone constante a todos los niveles de ingreso y es una medida directa de igualdad. La ley de Pareto se cumple casi tautológicamente con sólo suponer que a medida que el ingreso aumenta habrá un punto donde el número de personas que lo perciban será cero. En rigor, la esencia de dicha ley es que la tasa de disminución del número de ricos sea constante. No se pretende aquí abundar sobre la ley de Pareto porque solamente coincide con las distribuciones observadas a partir de cierto mínimo arbitrario que usualmente debe ser muy alto, y por lo tanto su aplicación a la distribución completa resulta discutible. ${ }^{6}$

La teoría de los procesos multiplicativos se basa en un principio conocido como ley del efecto proporcional, formulada por J. C. Kapteyn a principios del presente siglo y aplicada primero por $R$. Gibrat a la distribución del ingreso. Esta ley puede interpretarse de varias maneras. Una consiste en concebir al ingreso en el tiempo como una variable aleatoria que es a su vez producto de muchas variables aleatorias independientes que actúan en forma multiplicativa. Una manera de escribir en fórmulas lo anterior es

$$
Y_{t}=\left(1+r_{2}\right)\left(1+r_{2}\right) \ldots \ldots \ldots\left(Y_{t-2}\right)
$$

donde $Y_{\mathrm{t}}$ y $Y_{\mathrm{t}-1}$ son el ingreso en los tiempos $t$ y $t-1$ respectivamente. Los valores $r_{1}, r_{2}$, etc. son factores aleatorios independientes que deter-

1973; Amartya Sen, On Economic Inequality, Oxford, Clarendon Press, 1973. Puede verse también Jan Tinbergen, "A Positive and a Normative Theory of Income Distribution", The Review of Income and Wealth, Serie 16, Núm. 3, Rotterdam, 1970.

6 Sobre los procesos que generan la distribución del ingreso véase D. G. Champernowne, The Distribution of Income Between Persons, Londres, Cambridge University Press, 1973. El apéndice 6, p. 245, contiene una discusión relacionada con la distribución de Pareto. Champernowne es uno de los investigadores que más han contribuído al estudio e los procesos aleatorios en el caso de la distribución del ingreso. En L. Solís, La realidad económica mexicana: retrovisión y perspectivas, México, Siglo XXI Editores, 1970, pp. 298-307, pueden verse estimaciones de la constante de Pareto en el caso de México. 
minan los cambios en el ingreso. El efecto prolongado de estas tasas en el tiempo lleva a una distribución normal del logaritmo del ingreso, o sea a una distribución lognormal del ingreso. ${ }^{7}$

Una interpretación del logaritmo del ingreso es que denota el poder de los perceptores para adquirirlo. Al comparar el ingreso de dos personas, una con 1000 pesos y otra con 10000 , los logaritmos de estos ingresos ( 3 y 4 respectivamente si la base es 10 ) indican en cuánto puede cada individuo elevar la base. El primero puede elevarla al cubo y el segundo a la cuarta potencia. Con la transformación logarítmica los ingresos reflejan el hecho de que las oportunidades de cambios proporcionales en el ingreso son más homogéneas que las de cambios absolutos. Por este motivo se da al logaritmo del ingreso el nombre de poder del ingreso. ${ }^{8}$

El proceso multiplicativo aleatorio es inestable. La operación del proceso en el tiempo lleva a una distribución lognormal del ingreso con varianza creciente. Esta varianza puede interpretarse como una medida de concentración, según se explicará más adelante, y por lo tanto la inestabilidad del proceso significa que en el caso de la distribución del ingreso, ésta sería progresivamente más concentrada. La aplicabilidad del modelo lognormal era discutible en países como Inglaterra o Suecia, donde se observó una tendencia decreciente de la desigualdad. Champernowne, por ejemplo, objetaba "...que si las pequeñas causas fueran realmente independientes del tamaño del ingreso, éste se desparramaría hacia los extremos de pobreza y riqueza, de modo tal que la desigualdad aumentaría a tasa intolerable: en uno o dos siglos una gran proporción de los ingresos se habría vuelto extremadamente pequeña, a menos que el progreso del nivel de vida de la comunidad fuese tan rápido como para hacer solamente posible el aumento del ingreso e imposibles sus descensos..."9 Por ello se intentó formular un proceso multiplicativo con varianza constante, que implica que el ingreso personal y su tasa de crecimiento están en relación inversa. ${ }^{10}$

Se conjetura que en la mayoría de las economías latinoamericanas la distribución del ingreso sigue una trayectoria de deterioro sistemática, en cuyo caso las tribulaciones de Champernowne quedan resueltas. Más aún, el procedimiento utilizado para estabilizar el proceso, que según se dijo consiste en formular una relación inversa entre el ingreso y su tasa de crecimiento, sugiere analizar el caso contrario, o sea aquel donde el ingreso y su factor aleatorio de crecimiento están en relación directa. La exploración de este punto queda fuera del alcance de este

7 Véase J. Aitchison y J. A. C. Brown, The Lognormal Distribution, Londres, Cambridge University Press, 1969, en especial el Capítulo 3; y J. S. Cramer, Econometría empírica, México, Fondo de Cultura Económica, 1969, Cap. 4.

8 Ver Champernowne, op. cit., Caps. 2 y 3.

9 Ibid., p. 96.

10 La idea de estabilizar el proceso haciendo constante su varianza se debe a M. Kalecki; ver Aitchison y Brown, op. cit., Caps. 4 y 21. 
trabajo, aparte de que el número de observaciones disponibles sobre la distribución no permitiría llegar muy lejos.

En los párrafos anteriores, la aplicabilidad del proceso se examina en términos de la población total. Obviamente, la naturaleza de los factores aleatorios que inciden sobre el ingreso varían de un individuo a otro según su posición en el ciclo vital y la vida activa, y según su poder de percepción de ingresos en cuanto a educación, capital, etc. La población total es un agregado de cohortes. En cada una el proceso ha estado en operación durante un período que depende de la edad de la cohorte. Por lo tanto, la verosimilitud del proceso multiplicativo debe discutirse en términos de generaciones, cohortes o grupos de edad y no en relación con la población total. ${ }^{11}$

En efecto, si se estudia la conducta de la distribución del ingreso en poblaciones cerradas cuyos miembros abarcan individuos de todos los orígenes sociales, es factible que la distancia proporcional entre el ingreso de los pobres y los ricos aumente con el tiempo. En el caso de los países subdesarrollados la especulación anterior es todavía más viable. Por ejemplo, el ingreso de los hijos de campesinos de predios de temporal seguramente crece a tasas distintas al de los hijos de ministros, de tal manera que en los últimos años de edad de la cohorte la distancia será proporcionalmente mayor que al principio. La concentración de la población total resulta de la superposición de cohortes de concentración diferente. De este modo, la concentración del agregado queda en algún lugar entre la máxima y la mínima de las cohortes. El cambio en la concentración global será entonces resultado de cambios internos en las cohortes y del peso relativo de éstas; constará de dos componentes: una interna y otra entre cohortes. En los países desarrollados, puede suceder que la distancia entre cohortes disminuya con el tiempo y que la heterogeneidad interna sea constante o creciente.

En resumen, la clasificación de la población por edades y la conducta de la distribución del ingreso en cada categoría de edad son el camino para explorar el proceso. La edad clasifica el tipo de causas en operación que determinan el ingreso.

Antes de explorar numéricamente los aspectos anteriores, conviene ver con más detalle la conducta de la distribución en el tiempo. El cuadro 2 a continuación contiene la distribución familiar del ingreso en México, expresada como porciones del ingreso total que recibe cada $10 \%$ de la población en orden creciente de ingreso. El cuadro contiene además los ingresos medios de cada $10 \%$ de población corregido por cambios en los precios.

Se observa que hasta 1963 la concentración aumentó. Esto se ve en las porciones de ingreso de los estratos bajos. También, las tasas de crecimiento de los ingresos medios siguen cierta relación directa con el tamaño del ingreso; las de los estratos superiores son alrededor del doble de las de los inferiores. De este modo, hasta 1963 el crecimiento

11 Ver Cramer, op. cit., Cap. 4. 
Cuadro 2

MÉxico: Distribuciones DEL INGReso faMILIAR

\begin{tabular}{|c|c|c|c|c|c|c|c|c|c|c|c|c|c|}
\hline \multirow{2}{*}{\multicolumn{2}{|c|}{$\begin{array}{l}\text { \& de poblacoibn } \\
\text { on orden } \\
\text { oreoiente } \\
\text { de ingresos }\end{array}$}} & \multicolumn{2}{|c|}{1950} & \multicolumn{2}{|c|}{1958} & \multicolumn{2}{|c|}{1963} & \multicolumn{2}{|c|}{1968} & \multicolumn{3}{|c|}{ Ingreso mansual medio } & \multirow{2}{*}{$\begin{array}{l}\text { Creoimion to } \\
\text { anual medio }\end{array}$} \\
\hline & & \multirow{2}{*}{$\frac{x}{2.7}$} & \multirow{2}{*}{$\frac{\begin{array}{c}\text { Aoumu- } \\
\text { 1ado }\end{array}}{2.7}$} & \multirow{2}{*}{$\frac{x}{2.2}$} & \multirow{2}{*}{$\frac{\begin{array}{c}\text { Aoumu- } \\
\text { lado }\end{array}}{2.2}$} & \multirow{2}{*}{$\frac{\$}{2.0}$} & \multirow{2}{*}{$\frac{\begin{array}{c}\text { Acureu- } \\
1 \text { ado }\end{array}}{2.0}$} & \multirow[t]{2}{*}{$\%$} & \multirow[t]{2}{*}{$\begin{array}{c}\text { Aoumu- } \\
\text { lado }\end{array}$} & \multirow{2}{*}{$\begin{array}{l}1950 \\
258\end{array}$} & \multirow{2}{*}{$\begin{array}{l}958 \\
297\end{array}$} & \multirow{2}{*}{$\frac{1963}{315}$} & \\
\hline 1 & 10 & & & & & & & & & & & & 1.5 \\
\hline 2 & 10 & 3.4 & 6.1 & 2.8 & 5.0 & 2.2 & 4.2 & 4.2 & 4.2 & 325 & 375 & 356 & .7 \\
\hline 3 & 10 & 3.8 & 9.9 & 3.3 & 8.3 & 3.2 & 7.4 & & & 363 & 441 & 518 & 2.8 \\
\hline 4 & 10 & 4.4 & 14.3 & 3.9 & 12.2 & 3.7 & 11.1 & & & 421 & 516 & 598 & 2.7 \\
\hline 5 & 10 & 4.8 & 19.1 & 4.5 & 16.7 & 4.6 & 15.7 & 14.1 & 18.3 & 460 & 608 & 738 & 3.7 \\
\hline 6 & 10 & 5.5 & 74.6 & 5.5 & 22.2 & 5.2 & 20.9 & & & 526 & 789 & 834 & 3.6 \\
\hline 7 & 10 & 7.0 & 31.6 & 6.3 & 28.5 & 6.6 & 27.5 & & & 669 & 842 & 1056 & 3.6 \\
\hline 8 & 10 & 8.6 & 40.2 & 8.6 & 37.1 & 9.9 & 37.4 & 26.6 & 44.8 & 823 & $\begin{array}{lll}11 & 147\end{array}$ & 1592 & 5.2 \\
\hline 9 & 10 & 10.8 & 51.0 & 13.6 & 50.7 & 12.7 & 50.1 & & & 1033 & 1820 & 2049 & 5.4 \\
\hline 10 & 10 & 49.0 & 100.0 & 49.9 & 100.0 & 49.0 & 100.0 & 27.7 & 100.0 & 4687 & 6605 & 8025 & 4.2 \\
\hline
\end{tabular}

Fuente: Los datos para 1950, 1958 y 1963 fueron tomados del Banco Mundial de The Economy of Mexico Vol. II, 1973, p. 91, y los de 1968 de Banco de México, Oficina de Proyecciones Agrí́colas, Ingresos y

egresos familiares en 1968, México, 1973 (mimeografiado), p. 47. en 1968. 
del ingreso familiar seguía una trayectoria explosiva; la brecha entre los ingresos era creciente. Al comparar 1963 con 1968 se observa un cambio sustancial. La tendencia se invierte y por lo tanto la distribución mejora. Para entender mejor la magnitud del cambio véase ahora el cuadro 3 que contiene tres intervalos de ingresos comparables corregidos por cambios en los precios, pero ahora con un año base diferente. ${ }^{12}$

\section{Cuadro 3}

MéXICO: Distribución de familia SEgún ESTRATOS de INGRESOS, 1963 Y 1968

\begin{tabular}{cccc}
\hline Ingreso & \multicolumn{3}{c}{ Familias $(\%)$} \\
\cline { 2 - 4 } & 1963 & 1968 & Diferencia \\
\hline $0-845$ & 57.8 & 40.8 & -17.0 \\
$845-2535$ & 30.1 & 40.8 & +10.7 \\
$2536 \mathrm{y}$ más & 12.1 & 18.4 & +6.3 \\
\hline
\end{tabular}

Fuente: Cuadros 4 y 5 .

Se observa que de 1963 a 1968 el primer intervalo se redujo en $17 \%$ del total de familias y los dos intervalos restantes tuvieron saldos netos positivos. El segundo aumentó $10.7 \%$ y el tercero $6.3 \%$. En otras palabras, $17 \%$ de la población que percibía menos de 1000 pesos (de 1968) elev6 sus ingresos a mayor velocidad que el resto de la población. El cambio es ciertamente excepcional, y más por el hecho de que hasta 1963 las tasas de crecimiento de los ingresos mostraban conducta contraria. Es excepcional además porque pocos países del mundo han mostrado cambios de tal magnitud en tan corto tiempo. El cambio muestra una estructura del ingreso sumamente elástica. Según la información de 1968, la administración de Díaz Ordaz logró un cambio social importante.

\section{LA FORMA DE LA DISTRIBUCróN}

Antes de probar el ajuste de la distribución lognormal a las observaciones, es preciso describir la distribución y el método de estimación de sus parámetros. El tono críptico de las explicaciones a continuación es inevitable. Sin embargo, las fórmulas que se derivan se refieren exclusivamente a las características de la lognormal indispensables para juzgar su coincidencia con los datos observados. ${ }^{13}$

12 El crecimiento de los precios de 1963 a 1968 fue de $18 \%$ (deflactor implícito en el producto nacional bruto). En función de esto, el intervalo 0-845 de 1963 equivale al 0-1000 de 1968, el de 846 a 2535 equivale al 1001-3000, y el de 2356 y más al de 3001 y más.

13 El lector poco afecto para las fórmulas puede omitir esta sección. 
La función de distribución lognormal, según se explicó, es la normal del logaritmo de la variable aleatoria y desde luego sólo está definida para valores positivos de la variable. Esto significa que la distribución es asimétrica, porque al colocar el valor de la variable contra los valores de su función de densidad la figura se encoje a la izquierda, lo que da una curva con la cola derecha más larga (asimetría positiva). La función de densidad lognormal puede entonces encontrarse a partir de la normal. Si $Y$ es el ingreso y $u$ su logaritmo natural, entonces:

$$
L(Y)=N(u)
$$

es decir, la función de distribución (acumulativa) lognormal de $Y$ es igual a la normal de $u$. La función de densidad lognormal es entonces

$$
d L(Y)=\frac{d}{d u} L\left(e^{u}\right) \frac{d u}{d Y} d Y=\frac{1}{Y} d N(u)
$$

De este modo, la función de densidad lognormal es igual a la función de densidad normal del logaritmo de $Y$ dividida por $Y$. La lognormal tiene en este caso dos parámetros que serán denotados $\mu$ y $\sigma$, que son los valores esperados de $\log Y$ y de $(\log Y-\mu)^{2}$ respectivamente. La forma gráfica de la distribución es asimétrica a la derecha por lo que la media, la mediana y el punto modal quedan en posiciones diferentes (en orden descendente de derecha a izquierda).

Una propiedad de la lognormal es que en su momento $m(n)$ de orden $n$ respecto al origen es igual a la función generatriz de momentos de $N(\log Y)$, o sea la normal del logaritmo del ingreso. De la fórmula de la generatriz de momento de la normal se deduce entonces que: ${ }^{14}$

$$
m(n)=\exp \left(n \mu+n^{2} \sigma^{2}\right)
$$

Con esta fórmula pueden encontrarse las posiciones de la media y la mediana. La media aritmética de la distribución es:

$$
\text { Media aritmética }=\exp \left(\mu+1 / 2 \sigma^{2}\right),
$$

la mediana de la distribución es el punto medio de $d N(\log Y)$, es decir:

$$
\text { Mediana }=\exp (\mu)
$$

y el punto de la distribución queda ubicado donde $d L(Y)$ alcanza su valor máximo o sea,

$$
\text { Punto modal }=\exp \left(\mu-\sigma^{2}\right)
$$

14 El desarrollo detallado de todas las fórmulas a continuación puede verse en Aitchison y Brown, op. cit., Cap. 2. 
Para encontrar los valores de los parámetros de la lognormal con datos observados existen varios procedimientos. Una manera consiste simplemente en calcular la media de los logaritmos de los ingresos de los estratos y utilizarla como estimación de $\mu$. Respecto de $\sigma$, ésta se puede estimar también como la varianza de los ingresos medios observados. ${ }^{15}$ El procedimiento seguido aquí se basa en el teorema de que los cuantiles $C$ de orden $i$ de la lognormal y $C_{i}^{\circ}$ de la normal estándar están relacionados mediante la expresión

$$
C_{i}=\exp \left(\mu+C_{i}^{\circ} \sigma\right)
$$

Así al tomar logaritmos de esta fórmula se obtiene una forma lineal sobre la cual puede efectuarse una estimación por mínimos cuadrados. Gráficamente, la posición de los puntos se puede observar al colocar los cuantiles normales contra el logaritmo del ingreso. La distribución observada será lognormal en la medida en que los puntos queden dispuestos en línea recta (véase la gráfica 1). Debe aclararse que los cuantiles son magnitudes acumulativas y por lo tanto su ajuste no está libre de correlación serial. En la gráfica el ajuste se ve mejor de lo que es en realidad, o sea que se sobrestima el valor del coeficiente de correlación entre las variables.

\section{Estimación CON LAS OBSERVACIONES DE 1963 Y 1968}

En el cuadro A-1 del apéndice aparecen los números, las proporciones y los tamaños medios de las familias por estrato de ingreso, correspondientes a 1963. Las cifras de 1963 aparecieron con dos estratificaciones diferentes, una con 8 y otra con 16 categorías, que hizo posible formar las 21 categorías que aparecen en el cuadro 1. En el cuadro 3 aparecen los datos correspondientes a 1968, más una columna con el número medio de perceptores por familia. Los cuadros A-2 y A-4 del apéndice contienen los ingresos totales por categoría en 1963 y 1968, respectivamente. En todas estas tabulaciones aparecen además los valores calculados con la lognormal. Por razones ajenas a nuestra voluntad, la - encuesta de 1968 apareció con un despliegue de ingresos muy corto. Esto, desde luego, da una estimación dudosa del ajuste mínimo-cuadrático y obliga a hacer inferencias con más audacia.

La gráfica 1 contiene los cuantiles normales estándar formados con los valores observados, dispuestos contra el logaritmo del ingreso del límite superior de cada estrato. En la misma gráfica se han superpuesto las líneas estimadas. Nótese que las líneas calculadas subestiman el ingreso de los primeros estratos. Esto se debe a la existencia de dos puntos modales en la zona de ingresos bajos, como se explicará después.

15 Este procedimiento lo utiliza, por ejemplo, Polibio Cordova, Análisis econométrico de la distribución de ingresos, Departamento Administrativo Nacional de Estadística (DANE), Bogotá, 1973. 
Gráfica 1

México: Distribución DEL INGRESo, 1963 Y 1968

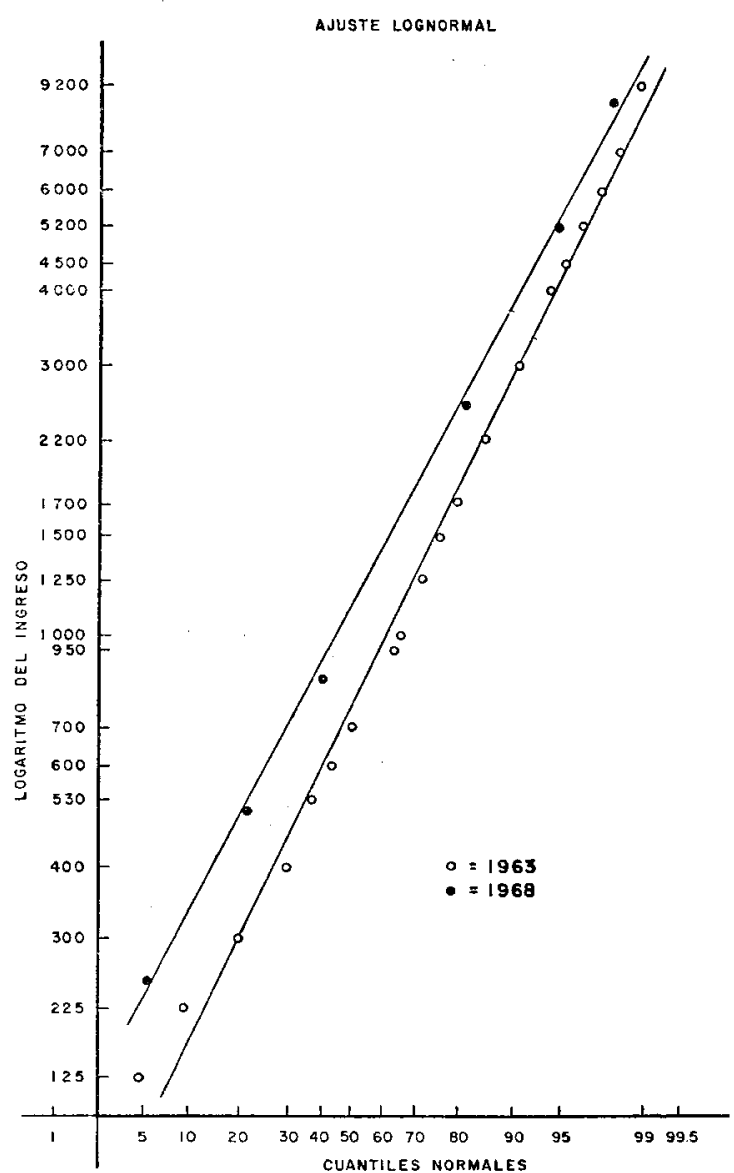

En el cuadro 4 del texto aparecen ahora las características de las estimación por mínimos cuadrados para 1963 y 1968 correspondientes a las líneas de la gráfica 1. El cuadro contiene dos estimaciones de $\sigma$ y $\mu$. Aunque el ajuste es razonable (los valores de $t$ de Student para $\sigma$ de 1963 y 1968 son 52 y 55, respectivamente), pero el índice de Durbin-Watson señala una correlación serial positiva. Por esta razón $\mu$ y $\sigma$ se reestimaron con un modelo autorregresivo de primer orden para intentar suprimir el efecto de la acumulación. Al hacerlo las estimaciones de $\sigma$ se elevan; su valor para 1963 aumenta proporcionalmente más que el de 1968 , lo que sugiere que el cambio entre los dos años fue en realidad más fuerte. Las gráficas 2 y 3 contienen las curvas de población observadas y ajustadas con la lognormal para $1967 \mathrm{y}$ 1968 , respectivamente. 
Cuadro 4

México: Características del ajuste lognormal, 1963 y $1968^{a}$

\begin{tabular}{|c|c|c|}
\hline & 1963 & 1968 \\
\hline$\sigma$ & 1.0277 & 0.9536 \\
\hline$\mu$ & 6.6346 & 7.0143 \\
\hline \multirow{2}{*}{ Error tiptoo de $\sigma$} & 0.02 & 0.02 \\
\hline & 1.1618 & 0.9857 \\
\hline$\mu$ & 6.4498 & 6.9757 \\
\hline Nodia aritustios & 1290 & 1753 \\
\hline Modiene & 761 & 1112 \\
\hline Punto modsl & 265 & 448 \\
\hline Medis aritudt1oo/modtane & 1,695 & 1.576 \\
\hline 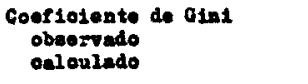 & $\begin{array}{l}0.54 \\
0.54\end{array}$ & $\begin{array}{l}0.49 \\
0.50\end{array}$ \\
\hline Indice Durbte-Watean & 0.32 & 1.17 \\
\hline $\mathrm{x}^{2}$ & 0.993 & 0.999 \\
\hline
\end{tabular}

2. La escala de ingresos de 1968 fue corregida por cambio en los precios (véase la nota 12).

\section{Gráfica 2}

MÉxico: Histogramas de población, observado y ajustado, 1963

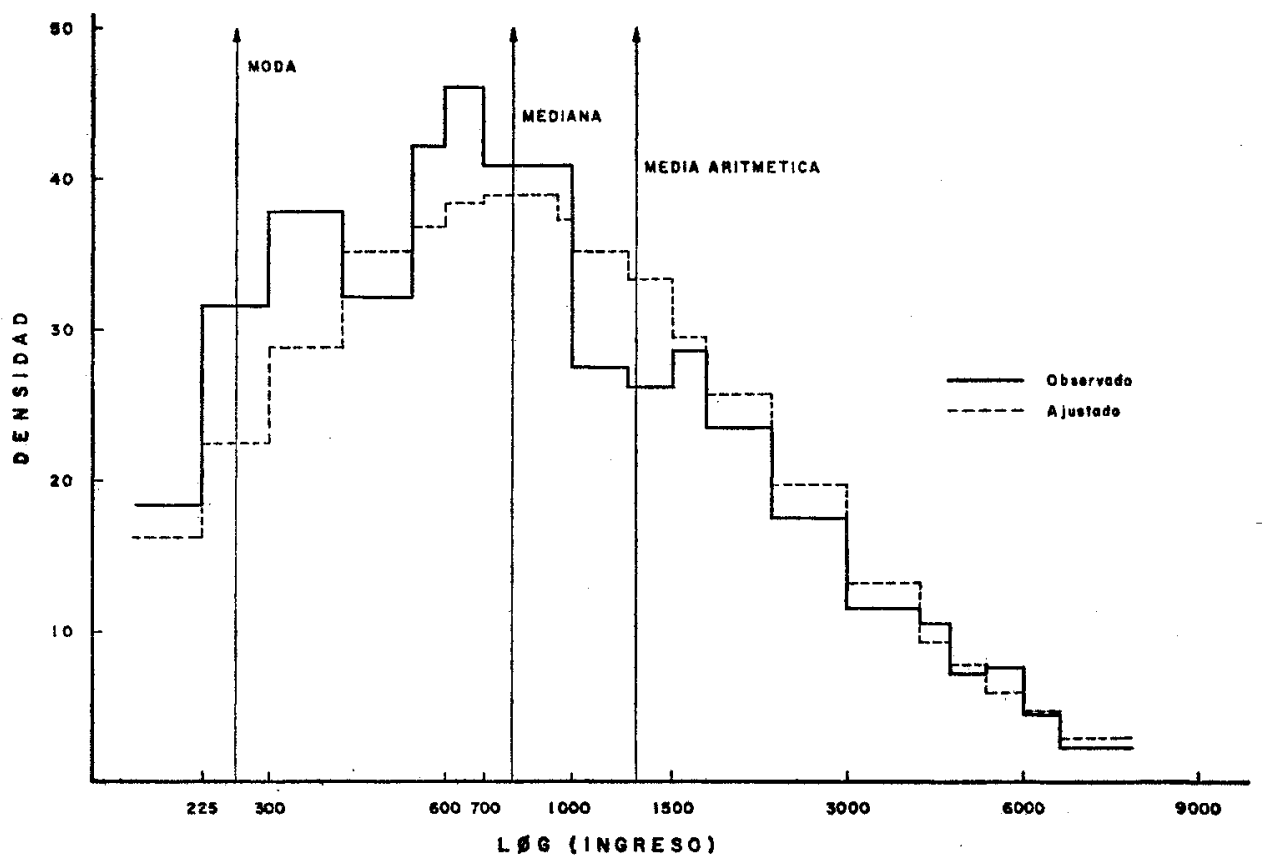


Gráfica 3

México: Histogramas de población, observado y AJustado, 1968

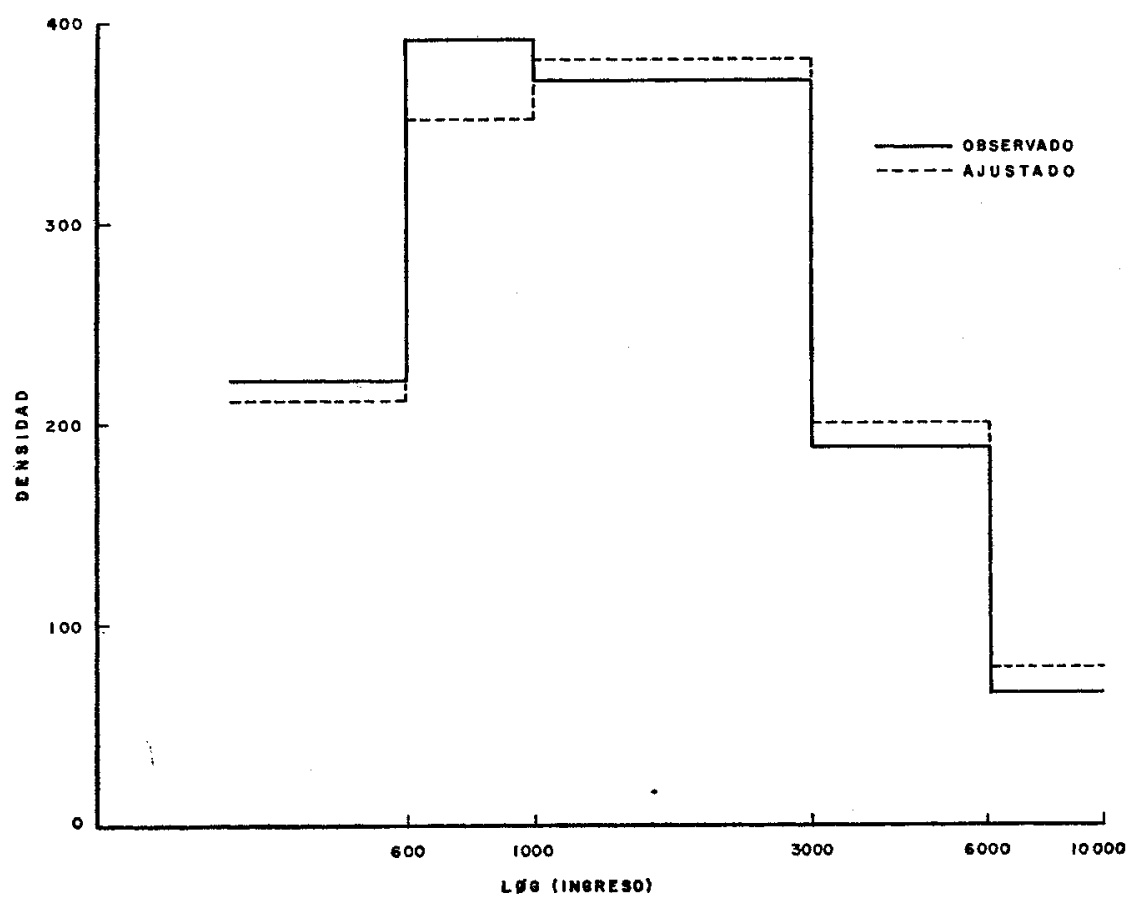

Según se señaló, la desviación típica $\sigma$ de la lognormal es una medida de concentración. La razón es que es la desviación cuadrática media de los logaritmos del ingreso alrededor del logaritmo de la media geométrica del ingreso. En otras palabras, la desviación típica de los logaritmos mide la distancia proporcional media entre los ingresos y la media geométrica. Cuando ocurre una redistribución del ingreso de los ricos a los pobres el valor de $\sigma$ disminuye, y su cambio es más fuerte cuando el flujo ocurre de los más ricos a los más pobres.

A medida que el ingreso de los más pobres aumenta, desciende la distancia entre la mediana y la media aritmética de la distribución. Dicho de otro modo, la asimetría de la curva es también reflejo de la concentración. El cociente entre la media aritmética y la mediana de la lognormal es exactamente igual al antilogaritmo de $0.5 \sigma^{2}$ (véanse las fórmulas anteriores) y sirve por lo tanto como medida de concentración simplemente porque es función creciente de $\sigma$. Por otra parte, dicho cociente coincide con el valor del cambio esperado de información. ${ }^{16}$

16 En H. Theil, Economics of Information Theory, Amsterdam, North Holland Publishing Co., 1967, p, 123-124, puede verse la demostración de que la información esperada es la mitad de la varianza de la lognormal. 
Para estudiar con más detalle el significado del cambio y el efecto de la agregación sobre los cálculos se han construido las curvas de Lorenz que aparecen en la gráfica 4. Las curvas, que contienen las porciones acumulativas de población en el eje horizontal y las de ingreso en el eje vertical, sirven para comparar visualmente las porciones acumulativas. Si las porciones de población e ingreso fueran iguales una a una, los puntos observados quedarían sobre la diagonal.

El índice de Gini es una función (lineal) del ingreso, igual a dos veces el área comprendida entre la curva de Lorenz y la diagonal e igual también a la mitad de la diferencia media relativa. Esta última es el promedio de las diferencias absolutas entre todos las porciones de ingreso (en este caso de los extratos). El coeficiente de Gini es también igual a

$$
G=0.5 \sum_{i, i}\left|p_{i} q_{i}-p_{i} q_{i}\right|
$$

En esta fórmula $p_{i}$ y $q_{i}$ son las participaciones de población e ingreso en el estrato $i .{ }^{17}$ Cuando la distribución es lognormal, el coeficiente de Gini puede deducirse formando la distribución acumulativa del ingreso (primer momento). Con ésta y la función original se puede estimar la diferencia media relativa. Después de tediosas manipulaciones, puede verificarse que el coeficiente de Gini de la lognormal equivale a restar uno a dos veces el área bajo la normal estándar hasta el punto $\sigma / / \vee 22$.

En el cuadro 4 aparecen los índices de Gini calculados con las observaciones y con las lognormales ajustadas. Nótese que sus valores son muy semejantes.

Las curvas de Lorenz de la gráfica 5 muestran que en 1968 en la zona central la elevada agregación de los estratos oculta la disparidad interna de un grupo de población muy amplio. El grupo cubre $41 \%$ de la población y $11.6 \%$ del ingreso. Esto, desde luego, redunda en una subestimación de las disparidades en 1968.

El histograma de la gráfica 3 muestra que la curva de población de 1963 tenía dos puntos modales. De 1968 la inferencia es más difícil por la agregación de los estratos; sin embargo, la bimodalidad es típica de las curvas de población. Las gráficas contienen también las curvas lognormales estimadas, lo que permite apreciar mejor el ajuste. Nótese que en la zona de ingresos bajos la curva ajustada a 1963 subestima el monto de población y luego en una zona entre el punto modal y la mediana, y alrededor de la media aritmética, la curva ajustada sobrestima la densidad. Globalmente, el ajuste lognormal sobrestima la población de ingresos altos pero en una proporción muy pequeña, según puede verse en los cuadros A-1 y A-3 del apéndice. La bimodalidad, desde lue-

17 Véase H. Theil, Statistical Decomposition Analysis, Amsterdam, North Holland Publishing Co., 1972, pp. 107-108 y 113. 
go, no puede reflejarse en la curva ajustada. Esto sugiere inmediatamente la necesidad de desagregar la curva de población en grupos con fuentes de ingreso homogéneas. Una explicación que suele darse a la bimodalidad es que el punto modal de la izquierda contiene individuos (jefes de familia en este caso) recién incorporados a la fuerza de trabajo cuyos ingresos son bajos. El segundo punto modal refleja, según esta interpretación, a la población de mayor antiguiedad en la actividad.

Se dijo antes que la distribución del ingreso en el agregado de familias era la superposición de procesos que operan en cada cohorte. La información de 1968 contiene datos por grupos de edad que permiten explorar el fenómeno en cada uno, aunque la información es de corte transversal y por lo tanto no es en rigor la historia de los cohor. tes en el tiempo.

El cuadro 5 contiene estimaciones de los parámetros lognormales de cada uno de 11 grupos de edad; muestra también la proporción de jefes de familia en cada grupo. La desviación típica, es decir, la concentración, aumenta con la edad. El aumento no es sistemático pero sí señala que la concentración en general es mayor en las edades superiores. Crece de .8355 a .9170 de los 20 a los 39 años de edad. Las cohortes comprendidas en esas edades abarcan el período de crecimiento del ingreso en los años intermedios de la edad activa. Nótese que la media aritmética del ingreso llega a un máximo en el grupo de edad de 50 a 54 años y luego desciende. La mediana del ingreso llega a su máximo en las edades de 40 a 44 años, donde la concentración al parecer disminuye, aunque ligeramente. Si la concentración inicial de cada gri.". po de edad de 20 a 39 años era igual, la concentración de las cohortes aumentó durante los veinte años que abarcan más o menos el período

\section{Cuadro 5}

Parámetros de la lognormal por grupos de edAd del JefE DE FAMILIA a 1968

\begin{tabular}{|c|c|c|c|c|c|c|c|c|}
\hline Idad & $\begin{array}{l}\text { Proporoion } \\
\text { de familias } \\
x\end{array}$ & $\begin{array}{l}\text { Coefioiente de } \\
\text { Determnaeion } \\
\left(R^{2}\right)\end{array}$ & $\sigma$ & $\begin{array}{l}\text { Error } \\
\text { tipioo } \\
\text { de } \sigma\end{array}$ & $\begin{array}{c}\text { Modia } \\
\text { ari tm6́tica }\end{array}$ & Mediana & $\begin{array}{l}\text { Nedia } \\
\text { aritustioa/ } \\
\text { mediana }\end{array}$ & $\begin{array}{l}\text { Indios } \\
\text { Durbin- } \\
\text { Watson }\end{array}$ \\
\hline $20-24$ & 3.2 & 0.995 & 0.8355 & 0.03 & 1393 & 982 & 1.418 & 2.27 \\
\hline $25-29$ & 9.4 & 0.993 & 0.8901 & 0.04 & 1499 & 1009 & 1.481 & 1.67 \\
\hline $30-34$ & 12.6 & 0.996 & 0.8981 & 0.03 & 1849 & 1235 & 1.497 & 1.37 \\
\hline $35-39$ & 14.4 & 0.998 & 0.9170 & 0.02 & 2008 & 1319 & 1.522 & 1.10 \\
\hline $40-44$ & 12.8 & 0.992 & 0.8866 & 0.04 & 2309 & 1558 & 1.482 & 1.10 \\
\hline $45-49$ & 14.0 & 0.996 & 0.9478 & 0.03 & 2311 & 1475 & 1.567 & 2.14 \\
\hline $50-54$ & 10.0 & 0.991 & 0.9657 & 0.05 & 2482 & 1557 & 1.594 & 1.86 \\
\hline $55-59$ & 7.2 & 0.998 & 1.0285 & 0.04 & 2433 & 1434 & 1.697 & 1.60 \\
\hline $60-64$ & 6.7 & 0.995 & 0.9627 & 0.04 & 2039 & 1283 & 1.589 & 1.65 \\
\hline $65-69$ & 4.9 & 0.997 & 0.9643 & 0.03 & 2002 & 1258 & 1.591 & 2.91 \\
\hline $70 \mathrm{y}+$ & 4.7 & 0.999 & 1.0205 & 0.01 & 1870 & 1111 & 1.683 & 2.10 \\
\hline
\end{tabular}

Fuente: Ingresos y egresos familiares en 1968, Banco de México, Oficina de Proyecciones Agrícolas, México, 1973 (mimeografiado); cuadro serie VI-3.

a El cuadro comprende $96 \%$ de las familias de 1968. 
de industrialización y crecimiento sostenido. La diferencia proporciunal entre las medias aritméticas en las edades 20-39 es mayor que la relación de medianas. En otras palabras, el ingreso de los estratos altos probablemente creció más que el de los estratos bajos. Las diferencias entre ingresos medios de las edades jóvenes y el ingreso medio máximo (a los 50-54 años) son más acentuadas, lo cual señala claramente que la población de ingreso bajo es la de menor edad, aunque la concentración dentro de los grupos de edad jóvenes sea menor. El descenso del ingreso en los últimos grupos de edad refleja ol retiro de la vida activa.

En resumen, la evidencia presentada sugiere que el proceso multiplicativo explicado refleja con fidelidad razonable la conducta de la distribución. El ajuste de la lognormal implica entonces que la concentración del ingreso va en aumento, contra lo que señalan los datos de 1968. Lo extraño de la información de 1968 es que la concentración del ingreso se redujo durante los años sesenta, pero la forma de la distribución permaneció igual. Por otra parte, la conducta de la distribución por grupos de edad es congruente con su posible deterioro a nivel global. En pocas palabras, los resultados de la encuesta de 1968, a la luz de lo expuesto, no son creíbles.

La tendencia de la distribución refleja el efecto de la política económica y de aquí su importancia; sin embargo, el estado de la distribución en el tiempo es también muy importante. Para entender mejor esto, véamos cómo es la distribución ahora que supuestamente mejoró. Según los datos de 1968, la población con ingresos familiares menores de $\$ 1000$, los gastaba según muestra el cuadro 6 .

\section{Cuadro 6}

MÉxico: Gasto medio mensual en estratos de INGRESO MENORES A $\$ 1000$ PESOS MENSUALES, 1968

\begin{tabular}{|c|c|c|c|c|c|}
\hline In Exedes & $\begin{array}{l}\text { Alimanton } \\
\text { bebidas } y \text { tabaoo }\end{array}$ & Babltaoton & $\begin{array}{l}\text { Bopa } y \\
\text { oalsado }\end{array}$ & Otros & (andllianes) \\
\hline $0-300$ & 199 & 36 & 29 & 42 & 1.6 \\
\hline $301-600$ & 323 & 60 & 54 & 71 & 1.3 \\
\hline $601-1000$ & 520 & 109 & 103 & 143 & 0.4 \\
\hline & & & & & 3.3 \\
\hline
\end{tabular}

Fuente: La misma del cuadro A-3 del apéndice.

Si el tamaño de la familia en estos estratos de ingreso va de 4.7 a 5.8 con un promedio aproximado de $\mathbf{5 . 2}$ miembos, el régimen alimenticio de estos individuos no debe ser muy bueno: cerca del 2.9 millones de familias de 5 miembros se alimentaban con un promedio de 250 pesos mensuales, equivalentes a 50 pesos mensuales por persona y a 1.65 pesos por día por persona. En estas circunstancias, el mejoramiento que antes se había calificado de poco creíble ahora se puede calificar de irrisorio. 


\section{LA DISTRIBUCIÓN FUNCIONAL}

La clasificación pertinente del sistema de remuneraciones a la fuerza de trabajo suele ser la de salarios e ingresos por capital. Esta es la distribución funcional del ingreso. Una corriente teórica supone que asalariados y capitalistas contribuyen a la producción y que el pago que reciben es proporcional a la contribución de cada uno. No se busca aquí ahondar en la validez de lo anterior, sino sólo señalar que la observación empírica más notable respecto de la distribución funcional del ingreso es que las participaciones de los salarios y el capital cambian con gran lentitud, y parecen ser constantes.

En los países industrializados se ha visto que la participación del trabajo aumenta lentamente y buena parte de la literatura económica se refiere a la explicación del cambio lento en la composición. En México, país de economía mixta, la participación de los salarios es mucho más baja que en los países industrializados y además parece descender. Sin embargo, las cifras existentes no coinciden ni siquiera en cuanto al orden de magnitud.

Las encuestas de 1963 y 1968 del Banco de México indican que la proporción de ingresos por salarios se redujo de $62.7 \%$ a $58.8 \%$ entre los dos años. Este cambio es compatible con la tendencia observada en la contabilidad del ingreso nacional, aunque el orden de magnitud es muy diferente. Según las cuentas nacionales la participación de los salarios en el producto interno bruto se redujo de 1950 a 1967 en forma tan sostenida como la tasa de crecimiento del producto. En 1963 y 1967 las participaciones fueron 30.2 y $27.3 \%$ en términos reales, respectivamente. ${ }^{18}$ Otra fuente más muestra que la participación del trabajo aumentó de $47.6 \%$ en 1963 a $53.1 \%$ en $1966 .{ }^{19}$ Las cifras de esta última fuente muestran oscilaciones en la participación entre 40 y $54 \%$ y aumentos continuados en los años 60.

La calidad de la información no la podemos juzgar, porque parece que su elaboración involucra algo más que las sumas y restas laboriosas de datos de cédulas censales y encuestas. De este modo, la elección de las cifras sólo puede provenir de ese otro conocimiento de la realidad mexicana del que aquí carecemos. Se desconocen también la naturaleza de los ingredientes econométricos utilizados para ensamblar las cifras. Por lo tanto diremos, sin heroísmos, que todas son incorrectas.

Los números presentados hasta aquí dejan muchas dudas sobre la conducta de la distribución personal del ingreso. Por una parte, la mag-

18 Cuentas nacionales y acervos de capital, consolidadas y por tipo de actividad económica, 1950-1967, México, Departamento de Estudios Económicos, Banco de México, 1969, cuadro 133. La diferencia entre los porcientos de una y otra fuente se debe sin duda a la enorme subdeclaración de ingresos no salariales en las encuestas de hogares. Por esta razón las únicas cifras que suelen coincidir son las de salarios.

19 Escuela Nacional de Economía, Un modelo de politica cconómica para México, 1970, cuadro 11, p. 43. 
nitud del cambio es exagerada y por otra las mismas fuentes señalan una baja en la participación del ingreso por salarios. Esto significaría que el mejoramiento de la distribución se debió a que aumentaron los ingresos de los empleados por cuenta propia y los patrones empleadores, lo cual hace aún menos creibles las cifras de 1968.

\section{EMPLEO Y DistribucióN}

Uno de los vehículos centrales de la política económica en relación con la distribución del ingreso es la política salarial y de empleo. Por esta razón conviene hacer algunos comentarios finales acerca del significado y el posible efecto de tales políticas. Otro renglón básico es, desde luego, la política fiscal, pero de esto no se hablará. ${ }^{20}$ La política salarial y de empleo interesa más en este contexto porque al parecer es la que recientemente ha recibido mayor apoyo.

La existencia de grupos de población pobre suele atribuirse al desempleo. Originalmente, se decía que gran parte de la fuerza de trabajo mexicana, igual que la de otros países de América Latina y Asia, estaba desempleada y por ello era pobre, aunque para algunos esto sonaba como una transliteración de la idea popular de que la causa de la pobreza es la falta de ganas de trabajar. Después, se decidió que el problema no era tal, sino uno de subempleo (término derivado de la noción de desempleo disfrazado acuñada por J. Robinson). El término así expresado sugería un punto en una especie de escala de intensidades del acto de trabajar. Luego el subempleo se asoció a la productividad de la fuerza de trabajo en una relación por demás obvia; la fuerza de trabajo ganaba poco porque producía poco. Con esta noción y una buena dosis de regresiones se llegó a estimaciones númericas de la cantidad de desempleados, definida como el desempleo abierto (los que ostentosamente no trabajan) sumado al desempleo equivalente, o sea la cantidad de trabajo que se podría suprimir de la actividad (por redundante) sin sacrificar el nivel de producción.

Como no hay ley natural ni ciencia algunas que definan el nivel mínimo de productividad (salvo en términos de costos), la política económica que se derivaría de tales estimaciones numéricas es llanamente la de elevar la productividad de toda la fuerza de trabajo, hasta donde alcancen los recursos para hacerlo, empezando desde abajo. En relación con los costos, la baja productividad significaría que el empleo de mano

20 Cabe señalar de paso que Pareto sostenía que la distribución del ingreso estaba determinada por causas naturales y que las políticas fiscales eran inocuas para alterarla. Existen también argumentos más categóricos al respecto. Sir Ernest Benn (1926) afirmaba que, según había demostrado el profesor Pareto, "si se colocan gráficamente los logaritmos del ingreso en la escala horizontal contra el logaritmo del número de personas con cierto ingreso o mayor en la escala vertical, los puntos observados quedarían aproximadamente en línea recta" y por lo tanto la igualdad distributiva era una "imposibilidad científica", citar do por R. H. Tawney, en Wealth, Income and Inequality, op. cit., p. 23. 
de obra cuesta más que el valor de lo que produce la unidad individual de producción. Esto sugiere la política de poner a "flotar" el precio del trabajo, pero sus consecuencias pueden ser negativas respecto de la distribución del ingreso, sin tener efecto positivo sobre el empleo. En Estados Unidos, por ejemplo, la elasticidad de la tasa de participación de la mano de obra respecto del salario no difiere sustancialmente entre la fuerza de trabajo de ingresos bajos y altos. ${ }^{21}$ Si la de los primeros es mayor, caso posible en México, entonces una política de empleo por la vía de reducir los salarios podría empeorar la distribución del ingreso. La mano de obra que primero se torna escasa es la calificada y por lo tanto empuja los salarios hacia arriba proporcionalmente más que los de la mano de obra no calificada. La baja del salario, por su parte, empeoraría la distribución funcional.

En otras palabras, la cuestión de que las remuneraciones son proporcionales a la productividad merece verificación empírica. La productividad es un concepto físico; es el número de unidades de producto generadas por unidad de tiempo. Su medición es enteramente ingenieril. El valor del producto o el precio del trabajo son conceptos económicos y su determinación ocurre en los mercados. En estos términos, cuando se dice, por ejemplo, que un campesino de temporal está subempleado, no queda claro si físicamente produce poco o si el precio de su producto es muy bajo. A este segundo caso corresponde mejor la noción de subremunerado. El problema del ingreso del campesino es una combinación de factores físicos y económicos y puede elevarse con sólo hacer otro tanto con el precio de lo que produce.

En el caso de gran número de campesinos pobres, su posición en la ocupación es la de patrón (poco más de $58 \%$ de la PEA rural) ${ }^{22}$ El problema de su bajo ingreso se sitúa en las operaciones del predio, no en el salario que recibe. De este modo, cuando se habla de la función de producción de un predio la noción resulta sumamente confusa. Por ejemplo, si se trata de una parcela donde la dotación de trabajo consiste del propietario y su familia, ¿qué cosa es el proceso de decisión sobre la cantidad de trabajo y capital a utilizar? No es tan obvio que el precio de estos factores influya sobre la decisión.

Para el planificador, el problema no consiste entonces en saber cuántos están subempleados, porque la definición es aplicable a cualquier número entre 0 y la fuerza de trabajo total. Más bien necesita una tabla con una escala de productividades físicas para que escoja el número que considere como límite del problema. Puesto así, la determinación del límite arbitrario de la productividad no es problema económico.

Un criterio que parece más sensato es el de definir el "subempleo" como el número de personas activas que perciben menos de cierto ingreso arbitrario. En tal caso el término "subempleo" es claramente desa-

21 E. S. Phelps, Inflation Policy and Unemployment Theory, Nueva York, W. W. Norton y Co., 1972, pp. 139-151.

22 Ver, Banco de México, Ingresos y egresos familiares en 1968, Oficina de proyecciones agrícolas, México, 1973. Cuadro p. 58. 
fortunado. Es obvio además que el criterio de ingresos mínimos contempla una redistribución del ingreso o de la riqueza como fórmula de planeación. La política económica que se puede derivar de este enfoque puede consistir en reubicar a la fuerza de trabajo subremunerada en actividades bien remuneradas, o bien en subsidiarla directamente. Por supuesto, no hay garantía de que lo anterior sea posible.

La estimación del número de subremunerados es sin duda tan arbitraria como la de subocupados. En este caso debe habilitarse al planificador con una curva de distribución del ingreso como las mostradas antes. En ella puede seleccionar el número que guste como umbral del decoro y con él estimar la magnitud del problema. ${ }^{23}$

El problema de fondo en la distribución del ingreso es el sistema productivo. Las políticas de empleo dirigidas a corregirlo consisten esencialmente en tomar recursos de las clases altas, sin que éstas lo noten, para estimular la formación de capital de las clases bajas, tratando de que éstas sí lo noten. Sin embargo, subsiste la pregunta de por qué el aparato productivo genera una distribución desigual que hay que corregir constantemente. Las políticas redistributivas no garantizan de manera alguna que el sistema económico se habrá de tornar más equitativo, ni que el cambio en las prioridades de inversión no tenga a largo plazo consecuencias negativas sobre el equilibrio.

Por otra parte, los desequilibrios observados en los últimos años en el sistema de precios sin duda han afectado negativamente la distribución del ingreso. Así, las políticas de empleo serán ahora un atenuante de la desigualdad. Una posibilidad en lo absoluto remota y que no parece haberse tomado en cuenta, es que en las circunstancias actuales la redistribución del ingreso sea francamente imposible. En efecto, el requisito científico elemental de toda solución —en este caso de una política para aumentar el empleo y mejorar la distribución- es la demostración rigurosa de la existencia de dicha solución.

23 En una investigación reciente se estimó que el número de personas activas cuya percepción era inferior al salario mínimo menor en cada entidad en 1970 era de 5.8 millones de personas. Véase El Problema ocupacional de México, Grupo de Estudio sobre el Empleo, inédito, Cuadro I, alternativa II. 


\section{Gráfica 4}

Curvas de Lorenz, 1963 y 1968

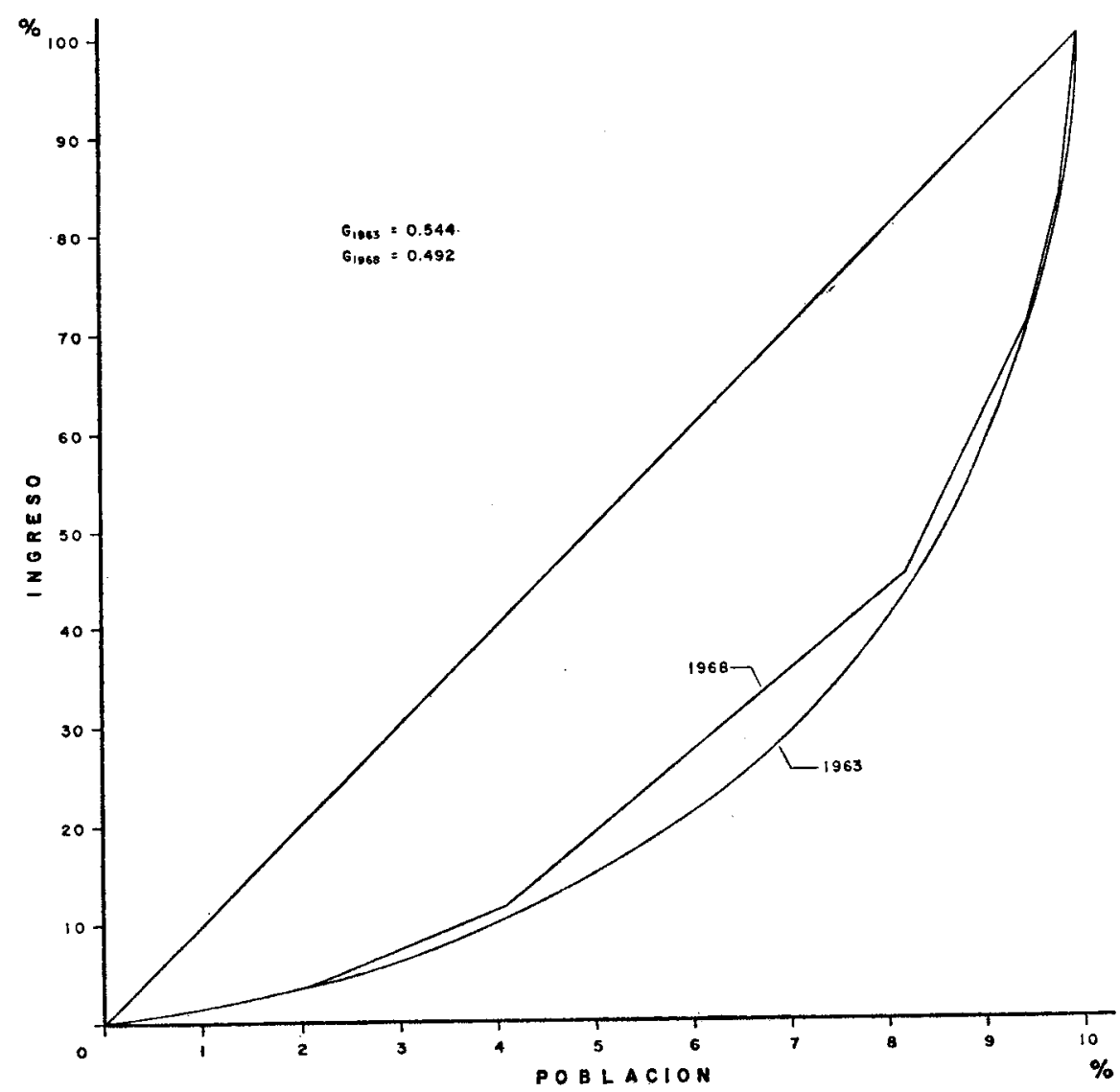




\section{APENDICE}

Cuadro A-1

MÉXICO: Distribuctón DEL INGREso FAMILIAR MENSUAL Y TAMAÑo DE LA FAMILIA, 1963

\begin{tabular}{|c|c|c|c|c|c|c|}
\hline \multirow[t]{2}{*}{ Fetrato } & \multicolumn{3}{|c|}{ Valoreg obaervados } & \multicolumn{2}{|c|}{ Valores osloulsdos } & \multirow{2}{*}{$\begin{array}{l}\text { Tamaño medio de } \\
\text { la fanilla }\end{array}$} \\
\hline & $\begin{array}{l}\text { Faniliag } \\
(\operatorname{miles})\end{array}$ & th & Eoumulado & $\bar{x}$ & $\begin{array}{c}\bar{x} \\
\text { coumulado }\end{array}$ & \\
\hline Total & 7330 & & & & & 5.76 \\
\hline $\begin{array}{r}\leq 175 \\
176-225 \\
226-300\end{array}$ & $\begin{array}{l}346 \\
337 \\
663\end{array}$ & $\begin{array}{l}4.72 \\
4.60 \\
9.05\end{array}$ & $\begin{array}{r}4.72 \\
9.32 \\
18.37\end{array}$ & $\begin{array}{l}7.64 \\
4.06 \\
6.44\end{array}$ & $\begin{array}{r}7.64 \\
11.70 \\
18.14\end{array}$ & $\begin{array}{l}4.77 \\
4.74 \\
5.21\end{array}$ \\
\hline$\leq 300$ & 1346 & 18.37 & & 18.14 & & 4.98 \\
\hline $\begin{array}{l}301-400 \\
401-530 \\
531-600\end{array}$ & $\begin{array}{l}795 \\
663 \\
383\end{array}$ & $\begin{array}{r}10.85 \\
9.04 \\
5.23\end{array}$ & $\begin{array}{l}29.22 \\
38.26 \\
43.49\end{array}$ & $\begin{array}{l}8.29 \\
9.89 \\
4.58\end{array}$ & $\begin{array}{l}26.43 \\
36.32 \\
40.90\end{array}$ & $\begin{array}{l}5.19 \\
5.76 \\
5.84\end{array}$ \\
\hline $301-600$ & 1841 & 25.12 & & 22.76 & & 5.53 \\
\hline $\begin{array}{l}601-700 \\
701-950 \\
951-1000\end{array}$ & $\begin{array}{l}521 \\
914 \\
149\end{array}$ & $\begin{array}{r}7.10 \\
12.47 \\
2.03\end{array}$ & $\begin{array}{l}50.59 \\
63.06 \\
65.16\end{array}$ & $\begin{array}{r}5.91 \\
11.90 \\
1.93\end{array}$ & $\begin{array}{l}46.81 \\
58.71 \\
60.64\end{array}$ & $\begin{array}{l}5.84 \\
5.82 \\
5.77\end{array}$ \\
\hline $601-1000$ & 1584 & 21.70 & & 19.14 & & 5.81 \\
\hline $\begin{array}{lll}1 & 001-1 & 250 \\
1 & 251-1 & 500 \\
1 & 501-1 & 700 \\
1 & 701-2 & 200 \\
2 & 201-3 & 000\end{array}$ & $\begin{array}{l}450 \\
351 \\
260 \\
445 \\
395\end{array}$ & $\begin{array}{l}6.14 \\
4.78 \\
3.54 \\
6.07 \\
5.39\end{array}$ & $\begin{array}{l}71.26 \\
76.04 \\
79.58 \\
85.65 \\
91.04\end{array}$ & $\begin{array}{l}7.80 \\
6.10 \\
3.69 \\
6.62 \\
6.09\end{array}$ & $\begin{array}{l}68.44 \\
74.54 \\
78.23 \\
84.85 \\
90.94\end{array}$ & $\begin{array}{l}5.77 \\
6.21 \\
6.21 \\
6.27 \\
6.23\end{array}$ \\
\hline $1001-3000$ & 1901 & 25.86 & & 30.30 & & 6.14 \\
\hline $\begin{array}{lll}3 & 001-4 & 000 \\
4 & 001-4 & 500 \\
4 & 501-5 & 200 \\
5 & 201-6 & 000\end{array}$ & $\begin{array}{r}241 \\
92 \\
68 \\
73\end{array}$ & $\begin{array}{l}3.33 \\
1.25 \\
0.92 \\
0.99\end{array}$ & $\begin{array}{l}94.37 \\
95.62 \\
96.54 \\
97.53\end{array}$ & $\begin{array}{l}3.80 \\
1.08 \\
1.11 \\
0.85\end{array}$ & $\begin{array}{l}94.74 \\
95.82 \\
96.93 \\
97.78\end{array}$ & $\begin{array}{l}7.30 \\
6.55 \\
6.55 \\
6.48\end{array}$ \\
\hline $3001-6000$ & 474 & 6.52 & & 6.84 & & 6.89 \\
\hline $\begin{array}{l}6001-7000 \\
7001-9200 \\
9201 \mathrm{yt}\end{array}$ & $\begin{array}{l}49 \\
46 \\
86\end{array}$ & $\begin{array}{l}0.67 \\
0.62 \\
1.18\end{array}$ & $\begin{array}{r}98.20 \\
98.82 \\
100.00\end{array}$ & $\begin{array}{l}0.68 \\
0.79 \\
0.75\end{array}$ & $\begin{array}{r}98.46 \\
99.25 \\
100.00\end{array}$ & $\begin{array}{l}6.48 \\
6.32 \\
6.66\end{array}$ \\
\hline $6001 \mathrm{~g}$ & 181 & 2.42 & & 2.22 & & 6.52 \\
\hline
\end{tabular}

Fuentes: Encuesta sobre ingresos y gastos familiares en México, 1963, Banco de México, Oficina de Estudios sobre Proyecciones Agrícolas, México, 1966, cuadros 18-1 y cuadro p. 432; e Ingresos y egresos familiares en 1968, Banco de México, Oficina de Estudios sobre Proyecciones Agrícolas, México, 1973, cuadro 2-1 (mimeografiado). 
Cuadro A-2

MÉXICO: INGRESOS TOTALES POR CATEGORÍA DE INGRESO, OBSERVADOS Y CALCULADOS (1963) E INGRESOS MEDIOS MENSUALES, 1963 Y 1968

\begin{tabular}{|c|c|c|c|c|c|c|c|}
\hline \multirow[t]{2}{*}{ : } & \multicolumn{3}{|c|}{ Observado } & \multicolumn{2}{|c|}{ Coloulado } & \multicolumn{2}{|c|}{$\begin{array}{c}\text { Ingreso observado } \\
\text { por familia (8) }\end{array}$} \\
\hline & $\begin{array}{l}\text { Ingroso } \\
(000000)\end{array}$ & $\$$ & $\stackrel{\$}{\%}$ & $\not$ & $\frac{\$}{\text { coumulado }}$ & 1963 & $1968^{8}$ \\
\hline Total & 9367 & & & & & 1278.0 & 1883.6 \\
\hline $\begin{array}{r}=175 \\
176-225 \\
226-300\end{array}$ & $\begin{array}{r}42 \\
69 \\
179\end{array}$ & $\begin{array}{l}0.45 \\
0.74 \\
1.91\end{array}$ & $\begin{array}{l}0.45 \\
1.19 \\
3.10\end{array}$ & $\begin{array}{l}0.84 \\
0.74 \\
1.43\end{array}$ & $\begin{array}{l}0.84 \\
1.58 \\
3.01\end{array}$ & $\begin{array}{l}122.0 \\
205.4 \\
269.6\end{array}$ & \\
\hline$\leq 300$ & 290 & 3.10 & 3.10 & 3.01 & & 215.4 & 216.1 \\
\hline $\begin{array}{l}301-400 \\
401-530 \\
531-600\end{array}$ & $\begin{array}{l}278 \\
309 \\
219\end{array}$ & $\begin{array}{l}2.97 \\
3.29 \\
2.34\end{array}$ & $\begin{array}{r}6.07 \\
9.36 \\
11.70\end{array}$ & $\begin{array}{l}2.36 \\
3.64 \\
2.11\end{array}$ & $\begin{array}{r}5.37 \\
9.01 \\
11.12\end{array}$ & $\begin{array}{l}349.4 \\
465.8 \\
571.8\end{array}$ & \\
\hline $301-600$ & 806 & 8.60 & 11.70 & 8.11 & & 437.8 & 419.2 \\
\hline $\begin{array}{l}601-700 \\
701-950 \\
951-1000\end{array}$ & $\begin{array}{l}336 \\
746 \\
145\end{array}$ & $\begin{array}{l}3.59 \\
7.96 \\
1.56\end{array}$ & $\begin{array}{l}15.29 \\
23.25 \\
24.81\end{array}$ & $\begin{array}{l}2.89 \\
7.47 \\
1.48\end{array}$ & $\begin{array}{l}14.01 \\
21.48 \\
22.96\end{array}$ & $\begin{array}{l}644.9 \\
816.0 \\
973.2\end{array}$ & \\
\hline $601-1000$ & 1227 & 13.11 & 24.81 & 11.84 & & 774.6 & 765.7 \\
\hline $\begin{array}{lll}1 & 001-1 & 250 \\
1 & 251-1 & 500 \\
1 & 501-1 & 700 \\
1 & 701-2 & 200 \\
2 & 201-3 & 000\end{array}$ & $\begin{array}{r}511 \\
482 \\
418 \\
866 \\
1026\end{array}$ & $\begin{array}{r}5.45 \\
5.14 \\
4.47 \\
9.25 \\
10.95\end{array}$ & $\begin{array}{l}30.26 \\
35.40 \\
39.87 \\
49.12 \\
60.07\end{array}$ & $\begin{array}{r}6.85 \\
6.88 \\
3.83 \\
9.48 \\
11.79\end{array}$ & $\begin{array}{l}29.81 \\
36.69 \\
40.52 \\
50.00 \\
61.79\end{array}$ & $\begin{array}{ll}1 & 135.6 \\
1 & 373.2 \\
1 & 607.7 \\
1 & 946.1 \\
2 & 597.5\end{array}$ & \\
\hline $1001-3000$ & 3303 & 35.26 & 60.07 & 38.83 & & 1737.5 & 1631.5 \\
\hline $\begin{array}{lll}3 & 001-4 & 000 \\
4 & 001-4 & 500 \\
4 & 501-5 & 200 \\
5 & 201-6 & 000\end{array}$ & $\begin{array}{l}841 \\
370 \\
354 \\
377\end{array}$ & $\begin{array}{l}8.98 \\
3.95 \\
3.78 \\
4.03\end{array}$ & $\begin{array}{l}69.05 \\
73.00 \\
76.78 \\
80.81\end{array}$ & $\begin{array}{l}9.78 \\
3.60 \\
4.22 \\
3.50\end{array}$ & $\begin{array}{l}71.57 \\
75.17 \\
79.39 \\
82.89\end{array}$ & $\begin{array}{ll}3 & 469.6 \\
4 & 021.7 \\
5 & 205.9 \\
5 & 164.4\end{array}$ & \\
\hline $3001-6000$ & 1942 & 20.74 & 80.81 & 24.60 & & 4097.0 & 3866.7 \\
\hline $\begin{array}{l}6001-7000 \\
7001-9200 \\
9201 \quad y+\end{array}$ & $\begin{array}{r}347 \\
365 \\
1087\end{array}$ & $\begin{array}{r}3.70 \\
3.89 \\
11.60\end{array}$ & $\begin{array}{r}84.51 \\
88.40 \\
100.00\end{array}$ & $\begin{array}{l}3.54 \\
4.88 \\
8.69\end{array}$ & $\begin{array}{r}86.43 \\
91.31 \\
100.00\end{array}$ & $\begin{array}{r}7081.6 \\
7934.8 \\
12606.2\end{array}$ & \\
\hline $6001-10000$ & & & & & & & 7191.8 \\
\hline $100001 y+$ & & & & & & & 16577.3 \\
\hline
\end{tabular}

a Corregidos por cambios en los precios.

Fuentes: Las mismas del cuadro 4. 
Cuadro A-3

MÉxico: Distribución DEL INGRESO FAMILIAR MENSUAL Y TAMAÑo DE LA FAMILIA, 1968

\begin{tabular}{|c|c|c|c|c|c|c|c|c|}
\hline \multirow[b]{2}{*}{ Eutreto } & & \multicolumn{3}{|c|}{ Obeorvado. } & \multicolumn{2}{|c|}{ Caloulado } & \multirow{2}{*}{$\begin{array}{l}\text { Tanatio } \\
\text { aodio do } \\
\text { la Fanilis }\end{array}$} & \multirow{2}{*}{$\begin{array}{l}\text { Mrimaro } \\
\text { podio do } \\
\text { poreoptoren } \\
\text { do ingrese }\end{array}$} \\
\hline & & Fanilied & $x$ & $\stackrel{x}{\text { sorminledo }}$ & 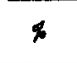 & ${ }^{4}$ & & \\
\hline Total & & 8151 & & & & & 5.8 & 0.9 \\
\hline$\leq$ & 300 & 438 & 5.4 & 5.4 & 6.06 & 6.06 & 4.7 & 0.1 \\
\hline $301-$ & 600 & 1257 & 15.4 & 20.8 & 14.55 & 20.61 & 5.5 & 0.9 \\
\hline $601-1$ & 000 & 1628 & 20.0 & 40.8 & 17.98 & 38.59 & 5.8 & 0.9 \\
\hline $1001-3$ & 000 & 3325 & 40.8 & 81.6 & 41.92 & 80.51 & 6.0 & 0.9 \\
\hline $3001-6$ & 000 & 1061 & 13.0 & 94.6 & 13.90 & 94.41 & 6.3 & 1.0 \\
\hline $6001-10$ & 000 & 275 & 3.4 & 98.0 & 3.97 & 98.38 & 6.1 & 1.0 \\
\hline $10001 \mathrm{~J}$ & & 167 & 2.0 & 100 & 1.62 & 100 & 5.9 & 1.1 \\
\hline
\end{tabular}

Fuente: Banco de México, Ingresos y Egresos Familiares en 1968, Oficina de Pro. yecciones Agrícolas, México, 1973 .

Cuadro A-4

MÉXICO: INGRESOS TOTALES OBSERVADOS Y CALCULADOS POR CATEGoRía DE INGRESO, 1968

\begin{tabular}{|c|c|c|c|c|c|c|}
\hline & & \multirow{2}{*}{ Ingreseo } & \multicolumn{2}{|c|}{ Observacto } & \multicolumn{2}{|c|}{ Galoulndo } \\
\hline & & & $\$$ & $\begin{array}{c}\% \\
\text { A oumenalado }\end{array}$ & $x$ & ${ }^{4}$ \\
\hline$\leq$ & 300 & 101 & 0.57 & 0.57 & 0.43 & 0.43 \\
\hline $301-$ & 600 & 560 & 3.15 & 3.72 & 2.71 & 3.14 \\
\hline $601-1$ & 000 & 1365 & 7.67 & 11.39 & 6.54 & 9.68 \\
\hline $1001-3$ & 000 & 5957 & 33.49 & 44.88 & 36.73 & 46.41 \\
\hline $3001-6$ & 000 & 4491 & 25.24 & 70.12 & 28.45 & 74.86 \\
\hline $6001-10$ & 000 & 2274 & 12.78 & 82.90 & 14.21 & 89.07 \\
\hline$\geq 10$ & 001 & 3041 & 17.09 & 100.00 & 10.93 & 100.00 \\
\hline
\end{tabular}

Fuente: Banco de México, Ingresos y egresos familiares en 1968, op. cit. a Millones de pesos. 